\title{
ANALISIS KADAR KREATININ PADA ANAK DENGAN LEUKEMIA LIMFOBLASTIK AKUT DI PUSAT KANKER ANAK ESTELLA BLU RSUP PROF DR RD KANDOU
}

\author{
${ }^{1}$ Fajrul Falakh Tamsil \\ ${ }^{2}$ Max F.J Mantik \\ ${ }^{2}$ Adrian Umboh \\ ${ }^{1}$ Kandidat Skripsi Fakultas Kedokteran Universitas Sam Ratulangi Manado \\ ${ }^{2}$ Bagian Ilmu Kesehatan Anak Universitas Sam Ratulangi Manado \\ Email: falakhftamsil@yahoo.com
}

\begin{abstract}
Malignant disease in children is one cause of death in the age group of children. Characteristic of the spread and prognosis of malignancy in children is very different with malignancy in adult. Acute Lymphoblastic Leukemia is the most common malignancy in children. Treatment with chemotherapy gifts a good effect in recent years, characterized by a decrease in mortality. How ever, as a vital organ that has function to stabilizer and organ disposal of substances that are not useful and toxic, surely chemotherapy effect on the health of kidney function. The impact of chemotherapy on renal function can be determined by examination of creatinne levels in children undergoing chemotherapy. The purpose of this study is to determine the levels of creatinine in children with acute lymphoblastic leukemia undergoing therapy in Estella Room BLU RSUP Prof Dr RD Kandou Manado. Characteristic of this study is descriptive analytic with retrospectional approach, this case done by taking patient's medical record data from September 2012-2013. Samples were 30. Conclusion:The result obtained from 30 samples contain as many as 16 samples had normal creatinine levels, and 14 samples had not normal creatinine levels, which consisted of 15 samples with a high risk group, an 15 sample with standard risk group. Bivariat analysis result show the value of $\mathrm{P}=0.642$. From this result, it can be concluded that there is no differences between creatinine levels in children with high risk group and children with standard risk group.
\end{abstract}

Keywords:Acute Lymphoblastic Leukemia, Creatinine, Child

Abstrak:Penyakit keganasan pada anak merupakan salah satu penyebab utama kematian pada kelompok umur anak.Kanker pada anak sangat berbeda dengan keganasan pada orang dewasa dalam sifat, penyebaran dan prognosis.Leukimia Limfoblastik Akut merupakan keganasan yang paling sering terjadi pada anak.Penanganan dengan kemoterapi memberikan efek yang baik dalam beberapa tahun terakhir, ditandai dengan penurunan angka mortalitas.Namun sebagai organ vital yang memiliki fungsi sebagai pengatur keseimbangan dan organ pembuangan zat-zat yang tidak berguna serta bersifat toksik, tentunya kemoterapi memberikan efek terhadap kesehatan fungsi ginjal. Dampak kemoterapi terhadap fungsi ginjal dapat diketahui dengan pemeriksaan kadar kreatinin pada anak yang menjalani kemoterapi. Tujuan penelitian ini untuk mengetahui kadar kreatinin pada anak dengan leukemia limfoblastik akut yang menjalani terapi di Ruang Estella BLU RSUP Prof. DR. R.D Kandou.Penelitian ini bersifat deskriptif analitik dengan pendekatan retrospektional, dalam hal ini dilakukan dengan pengambilan data rekam medik pasien sejak September 2012-2013. Sampel berjumlah 30 orang.Simpulan :Hasilyang didapatkan dari 30 orang sampel, terdapat sebanyak 16 sampel yang memiliki kadar kreatinin yang normal, dan 14 sampel yang memiliki kadar kreatinin yang tidak normal, yang terdiri dari 15 sampel dengan kelompok 
resiko tinggi(High Risk), dan 15 sampel dengan kelompok resiko standar (Standard Risk). Hasil analisis bivariat menunjukkan nilai p=0,642. Dari hasil penelitian ini dapat disimpulkan bahwa tidak adaperbedaan kadar kreatinin pada anak kelompok resiko tinggi (High Risk) $L L A$, dengan resiko standard (Standard Risk) LLA

Kata Kunci: Leukemia Limfoblastik Akut, Kadar Kreatinin, Anak.

Leukemia akut didefinisikan sebagai penyakit keganasan sel darah yang berasal dari sumsum tulang, ditandai dengan proliferasi sel-sel darah putih, dengan manifestasi sel abnormal dalam darah tepi. Leukosit dalam darah berproliferasi secara tidak teratur, tidak terkendali dan fungsinya menjadi tidak normal. Oleh karena proses tersebut, fungsi- fungsi lain dari sel darah normal juga terganggu hingga menimbulkan gejala leukemia.Leukemia akut pada anak-anak mencakup 30\%-40\% dari keganasan pada anak, yang dapat terjadi pada semua umur, insidens terbesar terjadi pada usia 2-5 tahun dengan insidens rata-rata 4-4,5 kasus/tahun/100.000 anak di bawah umur 15 tahun.2,3. ${ }^{1,2}$

Beberapa penelitian melaporkan bahwa proporsi pasien laki laki lebih besar dari pada perempuan, terutama terjadi setelah usia pertama kehidupan. Proporsi tersebut menjadi lebih dominan pada usia 6-15 tahun. Pada keseluruhan kelompok umur, rasio laki-laki dan wanita pada LLA adalah 1,15. Leukemia akut jenis LLA (leukemia limfoblastik akut) terdapat pada $\pm 90 \%$ kasus.

Diagnosis LLA ditegakkan dengan pemeriksaan aspirasi sumsum tulang, didapatkan komponen sumsum tulang mengandung 30\% sel muda (blast). Pasien dimasukkan kategori resiko tinggi (HR) bila jumlah leukosit darah tepi $>50.000 / \mathrm{ml}$, ditemukan sel blast pada susunan saraf pusat, jumlah total blast setelah 1 minggu diterapi lebih dari $1000 / \mathrm{mm}$, ada masa di mediastinum, dan umur $<1$ tahun atau $>10$ tahun. Remisi bila aspirasi sumsum tulang menunjukkan jumlah blast $<5 \%$ dari sel berinti. Umur pasien ditentukan berdasarkan data yang tercantum pada catatan medis dengan pembagian, <2 tahun, 2-5 tahun, 6-10 tahun dan $>10$ tahun. Penanganan dengan kemoterapi memberikan efek yang baik dalam beberapa tahun terakhir, ditandai dengan penurunan angka mortalitas.Namun sebagai organ vital yang memiliki fungsi sebagai pengatur keseimbangan dan organ pembuangan zat-zat yang tidak berguna serta bersifat toksik, tentunya kemoterapi memberikan efek terhadap kesehatan fungsi ginjal.,

Berdasarkan latar belakang masalah tersebut, penulis melakukan penelitian LLA untuk menganalisis kadar kreatinin anak LLA berdasarkan kelompok resiko di Pusat Kanker Anak Estella BLU RSUP Prof Dr RD Kandou.

\section{METODE PENELITIAN}

Jenis penelitian yang digunakan adalah deskriptif analitik dengan pendekatan retrospeksional, dalam hal ini dilakukan dengan pengambilan data rekam medic pasien sejak September 2012-2013. Waktu penelitian dilakukan pada bulan November - Desember 2013. Tempat penelitian dilakukan di Pusat Kanker Anak BLU RSUP Prof Dr RD Kandou Manado. Populasi adalah seluruh pasien anak yang menderita Leukemia Limfoblastik Akut di RSUP Prof.Dr.R.D.Kandou periode September 2012 - September 2013.. Sampel penelitian diambil berdasarkan kriteria inklusi yaitu : pasien anak yang menderita leukemia limfoblastik akut yang menjalani pengobatan kemoterapi di RSUP Prof Dr RD Kandou Manado. Analisis data dilakukan dengan uji fisher exactdengan menggunakan program SPSS.

\section{HASIL}

Tempat penelitian dilakukan di Pusat Kanker Anak Estella BLU RSUP ProfDr. RD Kandou Manado. Untuk memperoleh 
gambaran distribusi menurut karakteristik responden dapat dilihat pada tabel berikut:

Tabel 1. Distribusi sampel berdasarkan umur

\begin{tabular}{lcc}
\hline \multicolumn{1}{c}{ Usia } & Frekuensi & Persentase (\%) \\
\hline$<2$ & 0 & 0 \\
$2-5$ & 9 & 30 \\
$6-10$ & 17 & 56.7 \\
$>10$ & 4 & 13.3 \\
Jumlah & 30 & 100 \\
\hline
\end{tabular}

Tabel 1 menunjukkan bahwa kelompok terbesar responden terdapat pada usia 6-10 tahun, yaitu sebanyak 56,7\% diikuti usia 25 tahun sebanyak 30\%, dan terendah pada usia $>10$ tahun sebanyak 13,3\%.

Tabel 2. Distribusi sampel berdasarkan jenis kelamin.

\begin{tabular}{lcc}
\hline $\begin{array}{c}\text { Jenis } \\
\text { Kelamin }\end{array}$ & Frekuensi & $\begin{array}{c}\text { Persentase } \\
\text { \% }\end{array}$ \\
\hline Laki-Laki & 16 & 53.3 \\
Perempuan & 14 & 46.7 \\
Jumlah & 30 & 100 \\
\hline
\end{tabular}

Tabel 2 menunjukkan bahwa sampel dengan jenis kelamin laki-laki dengan persentase 53,3 \% lebih banyak dari sampel perempuan dengan persentase $46,7 \%$.

Tabel 3. Distribusi sampel berdasarkan resiko LLA

\begin{tabular}{lcc}
\hline \multicolumn{1}{c}{$\begin{array}{c}\text { Resiko } \\
\text { ALL }\end{array}$} & Frekuensi & $\begin{array}{c}\text { Persentase } \\
\mathbf{\%}\end{array}$ \\
\hline Standar & 15 & 50 \\
Risk LLA & 15 & 50 \\
High Risk & & \\
LLA & & 100 \\
Jumlah & 30 & \\
\hline $\begin{array}{l}\text { Dari tabel diatas terlihat bahwa frekuensi } \\
\text { sampel dengan High Risk LLA dengan }\end{array}$ \\
\multicolumn{2}{l}{ Standar Risk LLA sama yaitu sebesar 50\% }
\end{tabular}

Tabel 4. Distribusi sampel berdasarkan kadar kreatinin

\begin{tabular}{lll}
\hline $\begin{array}{l}\text { Kadar } \\
\text { Kreatinin }\end{array}$ & Frekuensi & $\begin{array}{l}\text { Persentase } \\
\text { \% }\end{array}$ \\
\hline Tidak & 14 & 46,7 \\
Normal & 16 & 53,3 \\
Normal & & \\
Jumlah & 30 & 100 \\
\hline
\end{tabular}

Dari tabel diatas terlihat bahwa frekuensi sampel yang memiliki kadar kreatinin tidak normal sebesar 46,7\%, sedangkan sampel yang memiliki kadar kreatinin yang normal sebesar 53,3\%.

Tabel 5. Analisis kadar kreatinin berdasarkan diagnosis

\begin{tabular}{|c|c|c|c|c|}
\hline \multirow{2}{*}{ Diagnosis } & \multicolumn{2}{|c|}{$\begin{array}{l}\text { Kadar } \\
\text { Kreatinin }\end{array}$} & \multirow{2}{*}{$\begin{array}{l}\text { To } \\
\text { tal }\end{array}$} & \multirow{2}{*}{$\begin{array}{c}\text { Fisher } \\
\text { 's } \\
\text { Exact } \\
\text { Test } \\
\text { P } \\
\text { (Value } \\
\text { ) }\end{array}$} \\
\hline & $\begin{array}{c}\text { Tidak } \\
\text { Normal }\end{array}$ & $\begin{array}{l}\text { Nor } \\
\text { mal }\end{array}$ & & \\
\hline ALL B & 7 & 8 & 15 & \\
\hline $\begin{array}{l}\text { Standar } \\
\text { Risk }\end{array}$ & & & & 0.642 \\
\hline $\begin{array}{c}\text { ALL B } \\
\text { High Risk }\end{array}$ & 7 & 8 & 15 & \\
\hline Total & 14 & 16 & 30 & \\
\hline
\end{tabular}

Berdasarkan tabel uji Uji Fisher Exact diatas nilai sig sebesar 0,642. Hal ini menunjukkan bahwa nilai sig $>0,05$

\section{BAHASAN}

Hasil analisis yang dilakukan memperlihatkan bahwa rata-rata usia sampel anak dengan leukemia dalam penelitian ini adalah 6 tahun dengan puncak insiden pada umur 6-10 tahun, dengan usia termuda adalah 2 tahun dan usia tertua adalah 16 tahun dan juga memperlihatkan bahwa jumlah responden laki-laki hampir sama dengan responden perempuan yaitu laki-laki berjumlah $53,3 \%$ sedangkan perempuan berjumlah 46,7\%, tampak jelas bahwa laki-laki lebih sering terkena dibanding perempuan

Hasil analisis perbandingan kadar kreatinin antara High Risk All dengan 
Standar Risk All, menunjukkan tidak adanya perbedaan antara keduanya, dengan dasar nilai $\mathrm{p}>0,05$. Pada penelitian ini tidak ditemukan adanya perbedaan pada kedua variable tersebut. Resiko tinggi LLA dengan kriteria yaitu usia $<1$ atau $>10$ tahun, jumlah leukosit $>50.000 / \mathrm{ul}$, atau telah terjadi penyebaran sel leukemia ke mediastinum, cairan otak, atau testis, memiliki kadar kreatinin yang sama dengan All dengan resiko standar. ${ }^{5}$

Selain itu menurut Protokol Indonesia 2006 adalah protocol yang di buat oleh Kelompok Kerja Hematologi Onkologi Indonesia dan ditetapkan oleh Ikatan Dokter Anak Indonesia untuk terapi pasien LLA. Protokol tersebut terbagi menjadi 2 skema berdasarkan kelompok resiko tadi, yaitu 3 fase (induksi, konsolidasi, pemeliharaan) untuk kelompok SR (resiko standard) dan 4 fase (ditambah reinduksi) untuk kelompok HR (resiko tinggi). ${ }^{5}$

Pada penelitian ini kadar kreatinin diambil pada saat kemoterapi fase induksi, karena tujuan pada fase ini ialah untuk mencapai keadaan remisi yaitu keadaan darah perifer normal, selularitas sumsum tulang normoseluler, dan jumlah limfoblas kurang dari 5\%. Untuk mencapai remisi sempurna kemoterapi harus bias menurunkan jumlah 99\% total sel leukemik. Pemberian kemoterapi seperti vincristine, glukokortikoid ditambah Lasparaginase dan antrasiklin dapat mencapai angka remisi 95\%. Pemakaian obat dalam fase induksi selain meningkatkan durasi remisi, namun juga dapat menimbulkan banyak komplikasi karena mielosupresi. Karena hal tersebutlah maka peneliti mengambil data kreatinin pada fase Induksi pada dua kelompok resiko tersebut.

Memang beberapa penelitian sebelumnya yang meneliti tentang perbedaan antara kedua kelompok resiko tersebut telah dikenal luas mempunyai perbedaan dalam hal outcome terapi maupun prognosis, dengan kelompok resiko tinggi dikaitkan dengan prognosis yang lebih buruk, selain itu manifestasi klinik antara LLA dengan resiko tinggi dengan resiko standar menunjukkan All dengan resiko tinggi lebih sering didapatkan hepatomegaly, spelenomegali, limfadenopati, dan leukositosis,selain itu jumlah pasien All dengan resiko tinggi yang meninggal dua kali lebih besar dari pasien resiko standar, namun penelitian ini belum menemukan adanya perbedaan kadar kreatinin antara keduanya.,

\section{SIMPULAN DAN SARAN}

Tidak ada perbedaan kadar kreatinin antara kelompok resiko tinggi (High Risk) dengan kelompok resiko standar (Standard Riskpada pusat kanker anak BLU RSUP Prof Dr RD Kandou Manado.

Berdasarkan hasil penelitian, melihat tidak adanya efek terhadap ginjal, penulis menyarankan untuk pengobatan dapat lebih agresif lagi agar target pengobatan yang dinginkan dapat lebih tercapai

\section{DAFTAR PUSTAKA}

1. Widiakara IM, Permono B, Ugrasena IDG, Ratwita M. Luaran pengobatan fase induksi pasien leukimia limfoblastik akut. Saripediatri. 2012

2. Pui CH. Treatment of acute limfoblastik leukimia. The New England Journal. 2012

3. Shipak MG. Cystatin C versus creatinine in determiningrisk based on kidney function. The New England Journal. 2010

4. Multasih S, Sutaryo, Sunarto, Yeoh A, Yeoh L, Mubarika S. Karakteristik klinis pasien leukemia limfoblastik akut (LLA) dengan fusi gen TEL-AML1, BCRABL, dan E2A-PBX1. Sari Pediatri. 2009 
5. Mia, Ugrasena IDG, Permono B. Pengelolaan medik anak dengan leukemia dan kemungkinan Perawatan di RS kabupaten. Divisi Hematologi-Onkologi BIKA FK Unair RSU Dr. Soetomo Surabaya. 2006

6. Pardede OS, Chunnaedy S. Penyakit Ginjal Kronik pada Anak. Departemen Ilmu Kesehatan Anak FKUI-RSCM. Sari Pediatri. 2009

7. Laboratorium Amerind Bio-Clinic. Uji Fungsi Ginjal. 2012 (cited 2013
Sep 20). Available from: http://www.abclab.co.id.

8. Multasih S, Sunarto, Sutaryo. Fusi Gen Translocation Ets LeukemiaAcute Myeloid Leukemia 1 (TelAml1) Sebagai Faktor Prognosis pada Leukemia Limfoblastik Akut Anak. Sari Pediatri. 2009.

9. Guyton, A. Hall, JE. Fisiologi Kedokteran. Edisi ke-11. Jakarta: Penerbit Buku Kedokteran EGC; 2008. 